\title{
CONTRIBUTION OF THE BIOMECHANICAL CRITERIA TO THE TEACHING AND LEARNING OF EXERCISES ON BALANCE BEAM
}

\section{Vladimir POTOP ${ }^{*}$, Vasilica GRIGORE², Mariana CÎMPEANU ${ }^{3}$, Victor BUFTEA ${ }^{4}$, Carolina MOGA ${ }^{4}$}

\author{
${ }^{1}$ Ecological University, Faculty of Physical Education and Sport, Bucharest, Romania \\ ${ }^{2}$ National University of Physical Education and Sport, Faculty of Physical Education and Sport, Bucharest, Romania \\ 3 "Dinamo" School Sports Club, Bucharest, Romania \\ ${ }^{4}$ State University of Physical Education and Sport, Chișinău, Republic of Moldova \\ *Corresponding author: vladimir_potop@yahoo.com
}

DOI: 10.35189/iphm.icpesk.2019.32

\begin{abstract}
This study is intended to determine the optimisation of teaching and learning exercises on balance beam based on biomechanical criteria. This scientific approach led to the organization of a case study with a female gymnast of 10 years old from the "Dinamo" School Sports Club of Bucharest. The research methodology involved the teaching by means of the linear and branching algorithmic programming for learning the content of the exercise on balance beam according to the requirements for Junior III category, level 2 of training. The efficiency of selecting the means of learning was ensured by the use of the biomechanical video analysis method, with two planes of study: sagittal and frontal. Preparatory and aiding exercises for strength, mobility and balance, executed at different levels on the floor, low beam and competition balance beam, were chosen during the teaching based on the biomechanical study. The study results highlight the development of the specific physical training and also demonstrate the improvement of the technical execution on the basis of biomechanical criteria. The results of the correlative analysis between the indicators of the specific physical training and the biomechanical analysis reveal strong and moderate connections between indicators. An optimal relation between the level of specific physical training and the means of teaching and learning the elements on balance beam in conformity with the requirements for Junior III category, level 2, contributes to improving the technical training level for successful participation in competition.
\end{abstract}

Keywords: balance beam, biomechanics, specific physical training, algorithmic learning, performance.

\section{Introduction}

At the present moment, artistic gymnastics is characterised by new trends and modern orientations of the training, which come from both the teaching technology field and the biomechanics field as a scientific branch, in order to know these mechanisms (Arkaev \& Suchilin, 2004; Nyman, 2019).

The balance beam, an event specific to women's artistic gymnastics, can be characterised above all as a balance apparatus, involving physical balance and mental balance as well (Vieru, 1997). According to the changes in the Code of Points (FIG, 2017), the balance beam routine must include a mount, some elements belonging to different structural groups (acrobatic, gymnastic and mixed elements) and some elements near the balance beam. The entire content must be characterised by dynamism, changes of rhythm and continuity. The end of the exercise (the dismount) must be consistent with both the difficulty of the whole and the specific requirements of the competition (Vieru, 1997).

In terms of biomechanics, mastering and adjusting the balance during the exercise on balance beam can be achieved by observing the logical principle of the permanent projection of the centre of body mass on the so narrow support surface (Gaverdovskij, 2007). As for the biomechanical particularities and characteristics on the balance beam, the following moments could be noticed: the role of the posture and muscle tone in keeping the static or dynamic balance, the push-off from the handstand position, where the technical details are explained by many specialists in the training and improvement process.

Regarding the technology that guides the learning process, Gaverdovskij (2007) shows the basic principles, the types of didactic programming (linear, branching and adaptive) and the technical means of learning.

The macro-methods of learning difficult acrobatic and gymnastic coordination exercises, but also the logicalstructural diagram for successful sports training are well presented by Boloban (1988). Thus, there are 11 basic elements of the macro-methods that form the dynamic system for learning gymnastic exercises during the basic specialisation stage of women's artistic gymnastics (Potop, Manole, \& Andreyeva, 2014; Potop, 2015; Boloban, 2010, 2013).

The methodology of learning balance beam exercises starts with learning these exercises on floor, then on the low beam, after which the accommodation is made with the surface that narrows and rises progressively, and finally the competition beam is used. The aiding apparatus used for the training of gymnasts on the balance beam 
are: gymnastics box, beam placed directly on the floor or a very low support, medium-height balance beam, felt sleeve or sponge placed on the balance beam in the right spot where the elements are executed, etc. (Vieru, 1997).

The purpose of the paper is to determine the contribution of the biomechanical criteria used in the teaching and learning of the balance beam exercise for the Junior III category, level 2 of training.

Hypothesis of the paper. We consider that an optimal relationship between the level of specific physical training and the means of teaching and learning the elements on balance beam in accordance with the requirements for Junior III category, level 2, will contribute to improving the technical training level for successful participation in competition.

\section{Material and Methods}

\section{Participants}

This scientific approach led to the organization of a case study with a female gymnast of 10 years old from the "Dinamo" School Sports Club of Bucharest. The subject volunteered to take part in this study after she had been fully informed about the testing requirements and conditions.

\section{Instruments and procedure}

The research was conducted in the gym of the "Dinamo" Sports Club of Bucharest during a period of $4 \frac{1}{2}$ months (from January to April 2019), 14 weeks with 6 training sessions/week. A training session is 210 min long, the workouts on balance beam last 30-40 min, and the specific physical training is 20-30 min. In order to assess the level of preparation for the balance beam, the study was divided into two stages, in which the gymnast was monitored twice every week (on Tuesdays and Thursdays), namely a total number of 28 tests (14 - the initial ones, and 14 - the final ones).

The research methodology involved the use of the linear and branching algorithmic programming method for teaching the content of the balance beam exercise in accordance with the requirements for Junior III category, level 2 of training (FRG [Romanian Gymnastics Federation], 2018).

The execution technique and the efficiency of selecting the means of learning for the balance beam were analysed by the video method using several recording devices (Samsung J3 - 2016 phone, Full HD Nikon and JVC GZ-E105BEU, Full HD, HDMI cameras). To highlight the execution errors, two planes of study were used: sagittal plane, with video recording from the right and from the left (perpendicular to the plane of motion), and frontal plane, with recording from the front and from behind (longitudinal to the plane of motion).

Within the teaching based on the biomechanical study, some preparatory and aiding exercises for strength, mobility and balance were selected and performed at different levels: on floor, on the low balance beam and on the competition beam (Potop et al., 2014).

The level of specific physical training was assessed using tests for the strength of the back and abdominal muscles (20 reps in sec), the arms (maximum number of reps), the shoulder girdle muscles - power handstand (maximum number of reps), the lower limbs - vertical jump (cm); balance while standing on tiptoes with arms up $(\mathrm{sec})$; mobility of the spine and shoulder girdle - the bridge $(\mathrm{cm})$; forward swings from the bridge with the right leg and left hand -10 reps (s) (Potop, Moraru, Timnea, \& Boloban, 2014).

The level of technical training on balance beam was assessed as follows: test 1, mixed series: slow walkover forwards + straight jump - in direct connection (points); test 2, slow walkover backwards with return to arabesque position on 1 knee (points); test 3, tumbling series: 2 flick-flacks backwards on 1 leg (points); test 4 , dismount by round-off back salto tucked (points).

Performance capacity: the full exercise executed in competition (points) at the National School Championships regarding score D (Difficulty), score E (Execution) and Final score.

\section{Statistical analysis}

The statistical analysis was made by means of the KyPlot and Microsoft Excel programs by calculating the descriptive indicators (mean, standard deviation $[ \pm \mathrm{SD}]$ ) of the specific physical training and technical training on balance beam. The calculation was done by means of the parametric method - t-test. The relationship between the indicators of the specific physical training and technical training on balance beam was analysed using the parametric method (Pearson correlation coefficient). 


\section{Results and Discussion}

The results of the specific physical training and technical training on balance beam for Junior III category, level 2 of training, are listed in Tables 1 and 2 (Potop, 2013).

Table 1. Results of the specific physical training

\begin{tabular}{|c|c|c|c|c|c|}
\hline \multirow[t]{2}{*}{ No. } & \multirow[t]{2}{*}{ Indicators } & \multicolumn{2}{|c|}{ Mean; \pm SD } & \multirow[t]{2}{*}{ t-test } & \multirow[t]{2}{*}{$\mathrm{P}$} \\
\hline & & Initial & Final & & \\
\hline 1 & Hanging leg raise on the rib stall - 20 reps (s) & $\begin{array}{l}33.84 \\
\pm 1.57\end{array}$ & $\begin{array}{l}30.64 \\
\pm 0.74\end{array}$ & 12.72 & $<0.001$ \\
\hline 2 & Trunk extension on the gymnastics box - 20 reps (s) & $\begin{array}{l}26.56 \\
\pm 1.88\end{array}$ & $\begin{array}{l}21.72 \\
\pm 1.83\end{array}$ & 68.33 & $<0.001$ \\
\hline 3 & Power handstand (max. no of reps) & $\begin{array}{c}3.43 \\
\pm 1.02\end{array}$ & $\begin{array}{c}6.21 \\
\pm 1.18\end{array}$ & -14.91 & $<0.001$ \\
\hline 4 & Push-ups (max. no of reps) & $\begin{array}{l}10.64 \\
\pm 1.59\end{array}$ & $\begin{array}{l}14.28 \\
\pm 1.86\end{array}$ & -16.19 & $<0.001$ \\
\hline 5 & In-place vertical jump $(\mathrm{cm})$ & $\begin{array}{l}43.28 \\
\pm 1.59\end{array}$ & $\begin{array}{l}39.78 \\
\pm 1.31\end{array}$ & 13.92 & $<0.001$ \\
\hline 6 & Balance tiptoe standing on the beam, arms up (s) & $\begin{array}{l}13.21 \\
\pm 2.93\end{array}$ & $\begin{array}{l}22.07 \\
\pm 3.85\end{array}$ & -12.21 & $<0.001$ \\
\hline 7 & Backbend to bridge $(\mathrm{cm})$ & $\begin{array}{l}25.71 \\
\pm 1.72\end{array}$ & $\begin{array}{c}30.5 \\
\pm 2.14\end{array}$ & -17.04 & $<0.001$ \\
\hline 8 & Left foot swing from bridge in 10 reps (s) & $\begin{array}{l}11.86 \\
\pm 0.77\end{array}$ & $\begin{array}{l}10.92 \\
\pm 0.61\end{array}$ & 11.73 & $<0.001$ \\
\hline 9 & Right foot swing from bridge in 10 reps (s) & $\begin{array}{l}11.49 \\
\pm 0.61\end{array}$ & $\begin{array}{l}10.16 \\
\pm 0.31\end{array}$ & 12.53 & $<0.001$ \\
\hline
\end{tabular}

Note: Paired t-test for mean difference

Table 2. Results of the technical training on balance beam

\begin{tabular}{llcccc}
\hline No. & \multicolumn{1}{c}{ Indicators } & \multicolumn{2}{c}{ Mean; \pm SD } & t-test & P \\
& & Initial & Final & & \\
\hline 1 & Mixed series: slow walkover forwards + straight & $8.44 ;$ & $8.95 ;$ & -7.17 & $<0.001$ \\
& jump - in direct connection (points) & \pm 0.24 & \pm 0.22 & & \\
2 & Slow walkover backwards with return to arabesque & $8.24 ;$ & $8.82 ;$ & -9.89 & $<0.001$ \\
& position on 1 knee (points) & \pm 0.22 & \pm 0.24 & & \\
3 & Tumbling series: 2 flick-flacks backwards on 1 leg & $8.16 ;$ & $8.57 ;$ & -12.01 & $<0.001$ \\
& (points) & \pm 0.19 & \pm 0.12 & & \\
4 & Dismount with round-off back salto tucked & $8.15 ;$ & $8.70 ;$ & -12.45 & $<0.001$ \\
& (points) & \pm 0.28 & \pm 0.21 & & \\
\hline
\end{tabular}

Table 3 shows the results of the performance capacity on balance beam concerning the Execution score in the check-up training sessions, initial and final tests, and the scores obtained in competition for Difficulty, Execution and Final score.

Table 3. Performance capacity on balance beam

\begin{tabular}{ccccc}
\hline \multicolumn{2}{c}{$\begin{array}{c}\text { Check-up training session } \\
\text { (points) }\end{array}$} & \multicolumn{3}{c}{ National School Championships (points) } \\
Initial & Final & Difficulty & Execution & Final score \\
\hline 8.000 & 8.400 & 4.000 & 8.200 & 12.200 \\
\hline
\end{tabular}

The correlative analysis between the indicators of the specific physical training and technical training on balance beam was made using the Pearson linear parametric method in the final testing, as shown in Table 4. 
International Proceedings of Human Motricity/ ICPESK 2019

Supplementary Issue of Discobolul - Physical Education, Sport and Kinetotherapy Journal, 2019

Table 4. Correlative analysis between the indicators of the specific physical training and technical training on balance beam in the final testing

\begin{tabular}{|c|c|c|c|c|c|}
\hline \multicolumn{2}{|c|}{ R, Pearson } & \multicolumn{4}{|c|}{ Technical training $(n=14)$} \\
\hline & & Test 1 & Test 2 & Test 3 & Test 4 \\
\hline \multirow{9}{*}{ 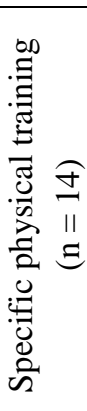 } & Test 1 & $.731 * *$ & -.479 & $-.676 * *$ & $-.751 * *$ \\
\hline & Test 2 & $-.886 * * *$ & $.551 *$ & $-.804 * * *$ & $-.908 * * *$ \\
\hline & Test 3 & $.848 * * *$ & $.673 * *$ & $.798 * * *$ & $.906^{* * *}$ \\
\hline & Test 4 & $.876 * * *$ & .493 & $.865 * * *$ & $.909 * * *$ \\
\hline & Test 5 & $-.930 * * *$ & $-.561 *$ & $-.773 * *$ & $-.958 * * *$ \\
\hline & Test 6 & $.904 * * *$ & .517 & $.685^{* *}$ & $.909 * * *$ \\
\hline & Test 7 & $.901 * * *$ & $.591 *$ & $.836 * * *$ & $.920 * * *$ \\
\hline & Test 8 & $-.812 * * *$ & -.568 & $-.785 * * *$ & $-.891 * * *$ \\
\hline & Test 9 & $-.809 * * *$ & -.398 & $-.818 * * *$ & $-.829 * * *$ \\
\hline
\end{tabular}

Note: Tests 1 to 9 - described in Table 1; Tests 1 to 4 - described in Table 2, * $-\mathrm{p}<0.05$; ** - p $<0.01$; *** - p $<0.001$

The results of the correlative analysis in test 1 for technical training (ThT), concerning the mixed series: slow walkover forwards + straight jump - in direct connection, highlight strong connections at $\mathrm{p}<0.001$ with all the tests of specific physical training (SPT), excepting test 1 , where $\mathrm{p}<0.01$; test 2 for ThT, referring to the slow walkover backwards with return in arabesque position on 1 knee, presents strong connections at $p<0.01$ with test 3 , Power handstand (max. no of reps), and at $\mathrm{p}<0.05$, with the tests SPT 1.5 and 7 , and poor connections with the tests SPT 1, 4, 6, 8 and 9, which, in practice, have a positive influence on the movement execution; test 3 for ThT, regarding the Tumbling series: 2 flick-flacks backwards on 1 leg have strong connections at $\mathrm{p}<0.001$ with SPT 2 , 3, 4, 7, 8 and 9 and strong connections at $\mathrm{p}<0.01$ with the tests SPT 1, 5 and 6; test 4 for ThT has strong connections at $\mathrm{p}<0.001$ with all the SPT tests, with the exception of test $1-$ SPT, where $\mathrm{p}<0.01$.

Figure 1 shows an example of preparatory exercise using the Kinovea program executed in the sagittal plane on the left (a), and in frontal plane from the front (b). This exercise is necessary to improve the slow walkover backwards, flick-flack on 1 leg, but also strength and mobility, highlighting the angular characteristics of segments and their deviations.

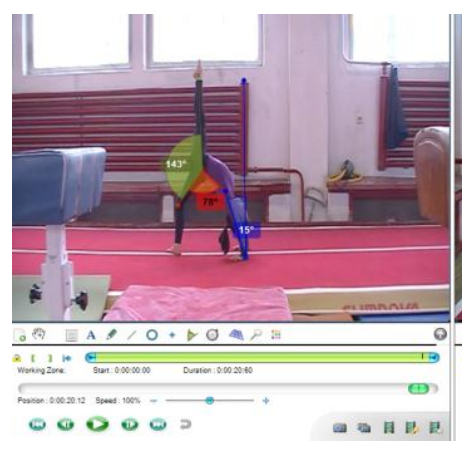

a) Sagittal plane

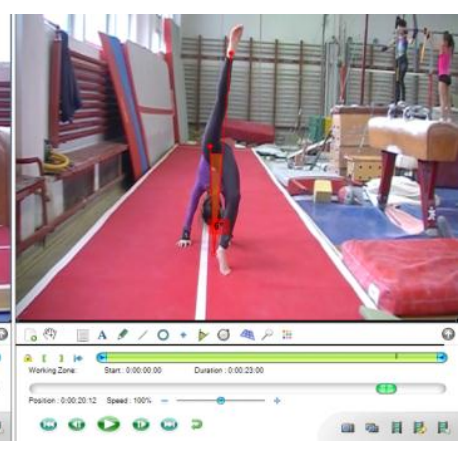

b) Frontal plane

Figure 1. Swing with 1 leg in the bridge position and keeping the vertical position

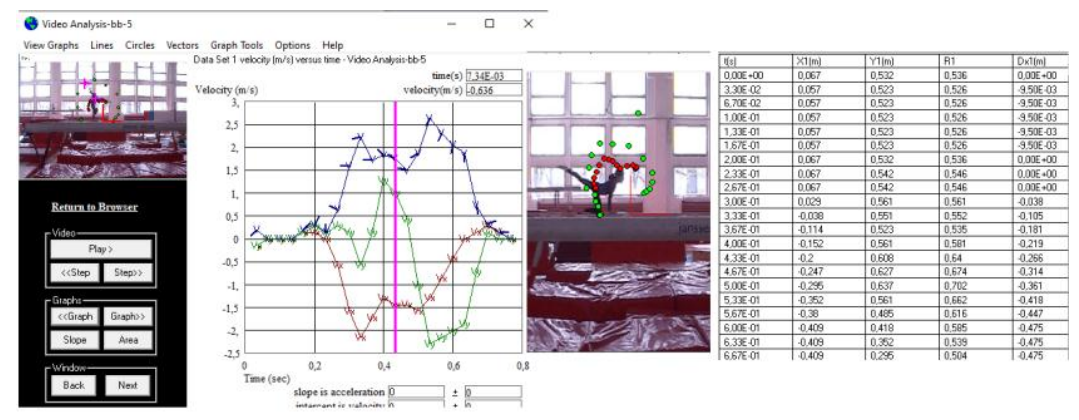


Figure 2. Physics ToolKit Software - slow walkover backwards with return to arabesque position on 1 knee + low part* (free)

Figure 2 shows the Physics ToolKit 2-D program of biomechanical analysis in the sagittal plane perpendicular to the plane of motion, in which one can see the trajectories of the centre body mass (the hip) and the segmental relationship: legs apart, shoulders, arms and even the left knee from support (Potop, Niculescu, \& Timnea, 2013).

Figure 3 shows the diagram of algorithms of the linear and branching programming for learning the balance beam routine in Junior III category, level 2 of training, the pedagogical tasks, aiding-preparatory exercises, supplementary exercises, the learning control and correction, and the learning outcomes (Potop, Grigore, \& Gavojdea, 2015; FRG, 2018).

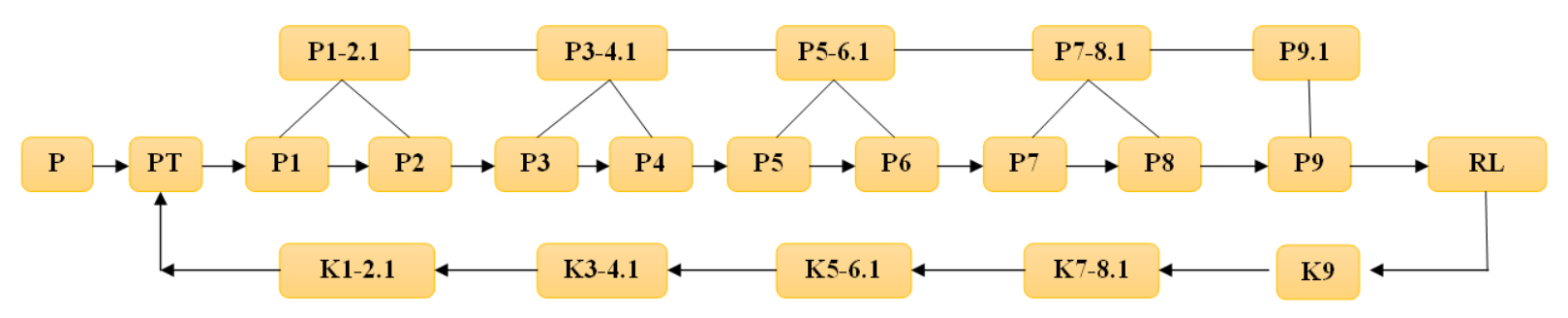

Figure 3. Algorithms of the linear and branching programming for learning the balance beam routine in Junior III category, level 2

Note: $\mathbf{P}$ - purpose of exercise learning; PT - pedagogical tasks; P1-9 - aiding/preparatory exercises; P1. Free mount with code value; P2. Marked handstand min. $1 \mathrm{sec}$ - in the routine; P3. Pirouette of minimum 360 degrees on 1 foot; P4. Gymnastics series: "pas" jump with "developpé" + "sissone" jump; P5. Gymnastics combination: take-off on 1 leg, the other one swings at minimum 90 degrees + backwards swing to arabesque position at min. horizontal + split jump (anterior-posterior /lateral); P6. Gymnastics combination: "grand battement" with the right foot, closed on 2 tiptoes, step and "grand battement" with the left foot, closed on 2 tiptoes; forward step with the left foot, closed on 2 tiptoes, then 90 degrees turn; lateral step with the left foot, closed on 2 tiptoes; lateral step with the left foot with 180 degrees turn, closed on 2 tiptoes; lateral step with the right foot closed on 2 tiptoes; lateral step with the right foot closed on 2 tiptoes, then 90 degrees turn on 2 tiptoes; backwards slow walkover with return to arabesque position on 1 knee + low part* (free); *combination of movements - elements near the balance beam, with a part of the trunk (including thighs, knees or head) in direct contact with the balance beam (no element needed). P7. Mixed series: slow walkover forwards + straight jump - in direct connection; P8. Tumbling series: 2 flick-flacks backward 1 leg - on balance beam; P9. Dismount: round-off back salto tucked. P1-2.1; P3-4.1; P5-6.1; P7-8.1; P9 Supplementary exercises of aiding - preparatory character; K1-2.1; K3-4.1; K5-6.1; K7-8.1; K9.1 - control, regulation and correction of the learning process, $\mathbf{R} \mathbf{L}$ - learning outcomes

The didactic structure of the program for learning the content of the balance beam routine was created taking into account the following elements: level of the physical and technical training of the gymnast; difficulty of the exercises necessary for the training, consistent with the syllabus content; interdependence and adequacy of the main and concrete goals; learning tasks; specific didactic principles, methods, means, elements of the regulation, control and correction process; learning outcomes by using the biological reverse afferentation (visual-motor, verbal-motor, visual-verbal, vestibular-motor).

This paper is based on a thorough scientific foundation in terms of biomechanical analysis of the acrobatic elements on balance beam in junior gymnasts aged 12-14 years and biomechanical analysis of sports performance technology in the balance beam dismount (Potop, Niculescu, \& Timnea, 2013; Potop, Rafal, Boloban, \& Otsupok, 2013). Our research analysed the influence of personality qualities on the competitive sports performance achieved in the balance beam event by junior gymnasts aged 12 to 15 (Potop \& Crețu, 2015), the implementation of elearning in the specific didactics for the balance beam in women's artistic gymnastics (Potop, Grigore, \& Gavojdea, 2015), the analysis of acrobatic tumbling exercises on floor and balance beam (Knoll, 1996), the attenuation of ground reaction forces in salto dismounts from the balance beam (Brown et al., 1996), the study of the kinematic variables of the Walkover Forwards gymnastic element (Diener-González, 2019), the assessment of the kinematic structure of indicative key elements of the exercise by postural orientation movements (Litvinenko, Niznikowski, \& Boloban, 2014), the determination of a relationship between the chosen parameters of aerial cartwheel on balance beam during the learning of this skill element (Aleksić-Veljković, Marković, \& Milčić, 2019). 


\section{Conclusion}

The study results highlight the level of the specific physical training in terms of increase of the strength of the abdominal muscles, scapula-humeral belt and legs; the improvement of the balance and joints mobility of shoulders, spine and coxofemoral spine.

It was also found out an improvement of the technical execution based on biomechanical criteria in terms of spatial-temporal characteristics (execution rhythm and tempo) and kinematic-dynamic characteristics specific to the linear motion and the translation with rotation motion.

The results of the correlative analysis between the indicators of the specific physical training and the biomechanical characteristics reveal strong connections at $\mathrm{p}<0.01, \mathrm{p}<0.001$ and $\mathrm{p}<0.05$ and moderate connections between indicators.

An optimal relation between the level of specific physical training and the means of teaching and learning the elements on balance beam according to the requirements for Junior III category, level 2, contributes to improving the level of technical training for successful participation in competition.

\section{References}

Aleksić-Veljković, A., Marković, K. Ž., \& Milčić, L. (2019). The relationship between chosen kinematic parameters of the aerial cartwheel on the balance beam during skill learning. Baltic Journal of Health and Physical Activity, 11(1), 18-23. DOI: 10.29359/BJHPA.11.1.02

Arkaev, L. J. \& Suchilin, N. G. (2004). Kak gotovit' chempionov: Teorija i tehnologija podgotovki gimnastov vyshej kvalifikacii [How to get champions: Theory and technology of gymnast training for qualifications]. Moskva: Fizkul'tura i Sport.

Boloban, V. N. (2010). Macro-method of teaching difficult acrobatic coordination exercises. Pedagogy of Physical Culture and Sports, 6, 14-24. (In Russian)

Boloban, V. N. (2013). Reguliaciia pozy tela sportsmena [Regulation of athlete's body posture]. Kiev: Olympic Literature.

Brown, E. W., Witten, W. A., Weise, M. J., Espinoza, D., Wisner, D. M., Learman, J., \& Wilson, J. (1996). Attenuation of ground reaction forces in salto dismounts from the balance beam. 14 International Symposium on Biomechanics in Sports (pp. 336-338). Funchal - Madeira, Portugal. Retrieved from https://ojs.ub.unikonstanz.de/cpa/article/view/2730

Diener-González, L. (2019). Artistic gymnastics: Biomechanics analysis walkover forward systematic review. Acciónmotriz, 22, 35-42. Retrieved from https://dialnet.unirioja.es/servlet/articulo?codigo=6920314

FIG. (2017). Olympic Code of Points. Romanian Gymnastics Federation.

FRG. (2018). Program de clasificare [Classification programme]. Federația Română de Gimnastică: Comisia Tehnică.

Gaverdovskij, J. K. (2007). Obuchenie sportivnym uprazhnenijam: Biomehanika. Metodologija. Didaktika [Sports training: Biomechanics. Methodology. Didactics]. Moskva: Fizkul'tura i Sport.

Knoll, K. (1996). Analysis of acrobatic tumbling exercises on floor and balance beam. 14 International Symposium on Biomechanics in Sports (pp. 325-328). Funchal - Madeira, Portugal. Retrieved from https://ojs.ub.uni-konstanz.de/cpa/article/view/2727

Litvinenko, Y. V., Niznikowski, T., \& Boloban, V. (2014). Evaluation of the kinematic structure of indicators key elements of sports equipment exercise by postural orientation movements. Physical Education of Students, 18(6), 29-36. https://doi.org/10.15561/20755279.2014.0606

Nyman, E. (2019). Biomechanics of gymnastics. In E. Sweeney (Ed.), Gymnastics medicine (pp. 27-54). Springer. Retrieved from https://link.springer.com/chapter/10.1007\%2F978-3-030-26288-4_3

Potop, V. (2013). Assessment of physical and technical training level in basic specialization stage in women's artistic gymnastics. Journal of Physical Education and Sport, 13(1), 114-119. DOI:10.7752/jpes.2013.01019

Potop, V. (2015). Principles of macro-methodic of junior female gymnasts' training to sport exercises for gymnastic all round competitions at specialized basic stage. Pedagogics, Psychology, Medical-Biological Problems of Physical Training and Sports, 19(8), 45-56. https://doi.org/10.15561/18189172.2015.0807

Potop, V., \& Crețu, M. (2015). Biomechanical characteristics of the synchronization of key elements of sport technique of the complex dismounts off beam. Journal of Physical Education and Sport, 15(2), 324-329. DOI:10.7752/jpes.2015.02049 
Potop, V., Grigore, V., \& Gavojdea, A-M. (2015). Implementation of e-learning in the specific didactics on balance beam in women's artistic gymnastics. In I. Roceanu (Ed.), Proceedings of the $11^{\text {th }}$ International Scientific Conference "eLearning and Software for Education" (Vol. 3, pp. 306-313). Bucharest, April 23-24, 2015. DOI: $10.12753 / 2066-026 \mathrm{X}-15-227$

Potop, V., Manole, C., \& Andreyeva, N. O. (2014). Biomechanical characteristics of the dismounts off beam of junior gymnasts 12-15 years old. Journal of Physical Education and Sport, 14(3), 406-412. DOI:10.7752/jpes.2015.02049

Potop, V., Niculescu, G., \& Timnea, O. C. (2013). A biomechanical analysis of the acrobatic elements on the beam at the level of junior gymnasts 12-14 years old. Palestrica of the third millennium - Civilization and Sport, 14(3), 205-211. Retrieved from http://www.pm3.ro/pdf/53/RO/13\%20-\%20potop\%20205-211.pdf

Potop, V., Moraru, C., Timnea, O. C., \& Boloban, V. (2014). Analysis of the influence of specific physical training on sports performances in female artistic gymnastics. Gymnasium - Scientific Journal of Education, Sports and Health, 15(1), 109-116. Retrieved from http://www.gymnasium.ub.ro/index.php/journal/article/view/179

Potop, V. A., Rafal, G., Boloban, V. N., \& Otsupok, A. P. (2013). Biomechanical characterization dismount from balance beam on the basis of the analysis of key elements of sports equipment. Pedagogics, Psychology, Medical-Biological Problems of Physical Training and Sports, 12, 58-66. DOI: 10.6084/m9.figshare.880619

Vieru, N. (1997). Manual de gimnastică sportivă [Textbook of sports gymnastics]. București: Driada. 